\title{
UNIFORM TENSION: THE PROBLEM AND THE SOLUTION
}

\section{A. Eremichev}

alexander.eremichev@akun.edu.tr

University Mediterranean Karpasia, Nicosia, N. Cyprus

\begin{abstract}
When we need to plot the failure surface of a material, the "starting point" is of great importance. It is determined by results of uniform compression and uniform tension tests. The former is rather trivial, although greater technical difficulties arise when creating a pressure high enough to make the material fail. Implementing a uniform tension stress state, however, and especially simultaneously measuring the failure stress is a complex scientific and engineering task. We supply a brief review of articles on the subject. We describe the sample and the device for implementing triaxial tension we developed. We provide test results for plexiglas (PMMA) and carbon-carbon composite material samples
\end{abstract}

\section{Keywords}

Test samples, uniform tension, uniform triaxial tension, finite element method, Drucker's postulate, plexiglas, carboncarbon composite material

Received 24.05.2017

(c) BMSTU, 2017

To determine the surface of strength [1], of great importance is the "starting point" which is determined by the results of tests on a uniform all-round compression and a all-round uniform tension.

The first definition is rather trivial, although associated with greater technical difficulties when creating the higher pressure at which the material collapses under compression. The creation of the stress state "all-round uniform tension" and especially the measurement of breaking stress at the same time, is a complex engineering task.

One of the greatest scientists and educators in the field of strength of materials Feodos'ev V.I. in the book [2] wrote:

"The only one method of the all-round homogeneous tension known at present time is the following: "The previously cooled solid homogeneous ball is quickly heated. The stress state indicated above will occur in the ball center. Unfortunately this method is not suitable for investigation of material properties under this state stress, for example for determining the so-called rupture characteristic".

This method was used by modern scholars [3]. Obviously are the difficulties to define specific values of the limit of the all-round tensile strength. Strength at all-round uniform tension in [3] is determined indirectly by finite element method (FEM).

Lately many works have been written which address the issues associated with the testing of materials under three axial tension. A review of these works is beyond the scope of this article. However, a large number of such works testify the importance of studying the properties of materials with uniform three-axis tensile. 
One of the ways to create a stress state almost exactly like all-round uniform tension is applied along three mutually perpendicular axes uniform tensile forces. The stress state arising from this can be called a uniform three axial tension (UTAT). The description of the device and the sample for the project are described in the article. In conclusion, the results of tests of samples of plexiglass and carbon-carbon composite material (CCCM) are given.

1. The author was offered a device which allowed to test in three axial tension using a standard testing machine [4] and a sample for such tests [5]. Detailed description the device is in [4]. The device is shown in Fig.1.

The advantage of the device is that the load increases proportionally on all three axes. If you set the same move at the top and bottom of the device (Fig. 1) which is possible with modern test machines, the center of the sample remains stationary.

The sample for uniform all-round tension [5] is developed in the form of a cube, having in the middle of each edge of the groove (Fig. 2). The grooves restrict the area of comprehensive stretching. As shown by the results of the experiments, the fracture surface passes through

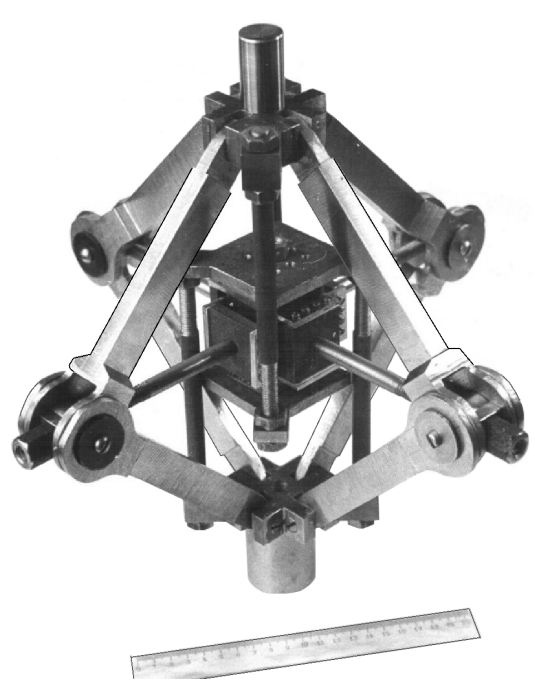

Fig. 1. Device for three axial tension this area and does not affect the part of the sample in contact with the grip.
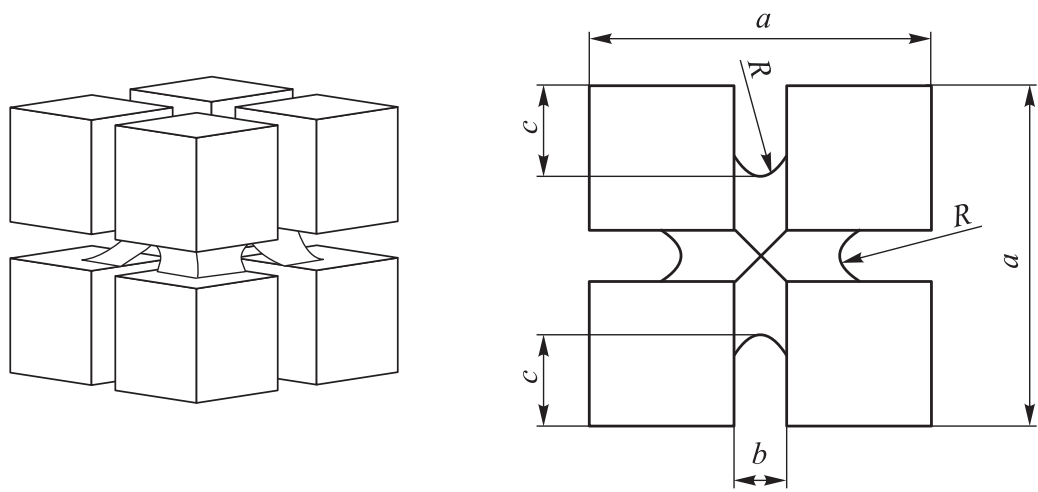

Fig. 2. The sample for the three axial tension

The shape and size of the sample chosen from the following simplified considerations.

Width $b$ and depth $c$ of the grooves in the sample should be such that the failure of the specimen occurred in the middle part of the tensile stress, not shear due to the impact of grippers of device. 
Calculating the tensile stress in the centre of the specimen and shear stress of capture and considering that most of the material breaking stress in shear is approximately half the breaking stress in tension will get

$$
a>4 c-b, r \leq \frac{c}{2} \text {. }
$$

More accurately the stress-strain state of the sample and final clarification of its size were made in [5] by FEM. The calculations were made for the samples with different sizes. Selection criteria of the final sample size was that to ensure the least stress concentration in the working area of the sample near its center (uniform three axial tension, and the virtual absence of shear stresses).

The allowable deviation from UTAT is equals no more than $10 \%$. For a sample with optimal size in UTAT stressed state is about $40 \%$ of the working area of the sample. Tensile stress in each of the three axes was $0,86 \sigma_{i i}$, where

$$
\sigma_{i i}=\frac{F}{(a-2 c)^{2}},
$$

$F$ - the tensile force acting on each of the three axes.

Therefore, the stress on the central section of the specimen differs only $14 \%$ different from the average stress $\sigma_{i i}$.

In samples with other dimensions this deference of tensile stress in the center of sample and also the stress concentration are greater.

The calculation was carried out in an elastic medium. For real materials, which at the time of destruction will have faced significant plastic deformation, stress concentrations will be lower.

The final specimen dimensions was selected as follows (Fig. 2)

$$
\frac{a}{10} \leq c \leq \frac{a}{7} ; \quad \frac{a}{9} \leq b \leq \frac{a}{7} ; \quad \frac{b}{5} \leq r \leq \frac{b}{2} .
$$

2. In the first stage of experimental investigations the tests were carried out for an isotropic material. The object of the study was chosen to be plexiglass, supplied in sheets with a thickness of $50 \mathrm{~mm}$. Series of samples (7 pieces) with the following dimensions were produced

$$
a=38,0 \mathrm{~mm}, b=8,0 \mathrm{~mm}, c=8,5 \mathrm{~mm}, r=4,0 \mathrm{~mm} .
$$

The tests were carried out using the device [3] (Fig. 1) on the serial testing machines FMG-200 at the velocity of the grippers of the machine of $0,2 \mathrm{~mm} / \mathrm{sec}$. Average results of test UTAT series samples are given in the table.

\begin{tabular}{|l|c|c|}
\hline \multicolumn{1}{|c|}{ The type of stress state } & Ultimate Strength $\sigma^{U}, \mathrm{MPa}$ & Energy (Joules) \\
\hline $\begin{array}{l}\text { Uniform three axes tension } \\
\text { UTAT }\end{array}$ & 9,79 & 14,41 \\
\hline Uniaxial tension UAT & 13,60 & 7,45 \\
\hline
\end{tabular}


For comparison, the same series (7 pices) of samples were tested with the use of the same device under the conditions uniaxial tension (UAT). In this case the grippers of the device was attached only to two opposite sides of the cubic sample. The results are shown in the third row of the table. Thus the comparison of test results of samples of UTAT and UAT becomes correct, since errors of transmission of forces through the device, stress concentration, etc. for different types of tests are almost the same.

The destruction of all samples occurred in the working area and not at the area of attachment of the grips, which indicates their suitability.

For all the samples as in UTAT and in UAT by using the diagram of the apparatus of the testing machine were recorded the diagram "force-move of grips of testing machine". As these diagrams for all samples were linear, then the energy of rupture of the sample can be calculated as half of the product of maximum force by the move of the grip. The average value ( 7 pices) of this energy is given in the last column of the table.

For discussion of the obtained results let us consider an isotropic material with equal strength in all three axes $\sigma^{U}$. Plexiglass is such a material. The time of the destruction at uniaxial tension is depicted by points lying on the axes of a rectangular coordinate system $\sigma^{U}, 0,0 ; 0, \sigma^{U}, 0 ; 0,0, \sigma^{U}$. The postulate of Drucker, says that the surface of plasticity should not be sunken [1]. By analogy we can assume that the surface of strength should also not be sunken. In the limiting case, this may be the plane passing through the above point. The case of UTAT would correspond to a beam having equal angles with all three axes. By simple geometry it can be shown that the ultimate strength under UTAT $\sigma_{\mathrm{UTAT}}^{U}$ is $\sqrt{3}=1,73$ times less than in uniaxial tension

$$
\sigma_{\mathrm{UAT}}^{U} / \sigma_{\mathrm{UTAT}}^{U}=1,73 \text {. }
$$

Again, note that the above is the case if the surface strength flat.

The results given in table show that

$$
\sigma_{\mathrm{UAT}}^{U} / \sigma_{\mathrm{UTAT}}^{U}=1,39
$$

which indicates either an error of the results of the experiments or of the fact that the surface of strength are slightly convex.

A very important result which is in need of further reflection and discussion is that. Despite the lower strength of the samples at UTAT than UAT accumulated sample energy to the point of destruction in the first case were almost two times greater. This indirectly suggests that in the case of UTAT energy failure criteria may be more preferable.

The recently published article [6] provides the test results of samples [5] from polymethyl methacrylate with sample sizes coinciding with the sizes of our articles. The main conclusions of this article coincide with the content of our publications.

3. In a similar way, tests were carried out with two series of samples of carboncarbon composite material (CCCM) of the type 3D. The first series had the size 


$$
a=38,0 \mathrm{~mm}, b=8,0 \mathrm{~mm}, c=10,0 \mathrm{~mm}, r=4,0 \mathrm{~mm}
$$

and the second

$$
a=38,0 \mathrm{~mm}, b=6,0 \mathrm{~mm}, c=6,3 \mathrm{~mm}, r=3,0 \mathrm{~mm} \text {. }
$$

Samples of the first series were almost the same as tested earlier plexiglas samples. For CCCM the depth and width of the groove led to the destruction of the sample not at the working area, and to the "puckering" of the carbon fibers of those parts of the sample, which is attached to the gripper of device. It is associated with a significantly lower binding strength compared with the strength of carbon fiber. The destructive stress in this case was very little of $0,507 \mathrm{MPa}$ to $0,863 \mathrm{MPa}$.

The second series of samples from CCCM have reduced width and depth of grooves. This has led to the growth of destructive stresses almost 20 fold. However, in this case, the destruction of the samples occurred not in the working area. Observed cracking close to one of the grips of the device. Stresses in the working area of the sample at this point was approximately $25 \%$ of the tensile strength CCCM under uniaxial tension.

Thus, the task to determine the strength under three axial tension CCCM at this stage of the work failed. In our opinion it is necessary to increase the size of samples $a$ and a relative decrease in the depth $c$ and width $b$ of groove. It is connected with great difficulties due to the high value of the samples CCCM and the limited capacity of the test equipment.

Conclusion. The device and the sample, which can be successfully applied to study the properties of materials under three axial tensile were developed.

The proposed method of test for three axial tension can be successfully applied to orthotropic materials such as plexiglass.

The use of the above described methods for investigation of materials like CCCM requires further development. It is necessary to increase the size $a$ of samples and a relative decrease in the depth $c$ and width $b$ of groove.

\section{REFERENCES}

[1] Wu H.-C. Continuum mechanics and plasticity. Chapman \& Hall/CRC Press, 2005. 684 p.

[2] Feodos'ev V.I. Advanced stress and stability analysis. Berlin, Heidelberg, Springer-Verlag, 2005. $421 \mathrm{p}$.

[3] Doquet V., Ben Ali N., Constantinescu A., Boutillon X. Fracture of a borosilicate glass under triaxial tension. Mechanics of Materials, 2013, vol. 57, pp. 15-29.

DOI: $10.1016 /$ j.mechmat.2012.10.008

Available at: http://www.sciencedirect.com/science/article/pii/S0167663612001810

[4] Eremichev A.N. Ustroystvo dlya trekhosnogo nagruzheniya obraztsa nagruzkami odnogo znaka [Test device for uniform triaxial tensile]. Patent USSR 1499170. Appl. 18.06.1987. Publ. 07.08.1989.

[5] Eremichev A.N., et al. Obrazec dlya ispytanij na ravnomernoe trekhosnoe rastyazhenie [The speciment for testing at uniform triaxial tension]. Patent USSR 1762165. Appl. 10.04.1990. Publ. 15.09.1992. 
[6] Tsvetkov S.V., Kulish G.G., Smerdov A.A., Baryshev A.N., Tashchilov S.V., Magnitskiy I.V., Ponomarev K.A. Experimental research of materials in triaxial tension. Vestn. Mosk. Gos. Tekh. Univ. im. N.E. Baumana, Mashinostr. [Herald of the Bauman Moscow State Tech. Univ., Mech. Eng.], 2016, no. 5, pp. 76-88 (in Russ.). DOI: 10.18698/0236-3941-2016-5-76-88

Eremichev A. - Assoc. Professor, Dr., Head of Aviation Department, University of Mediterranean Karpasia (Sht. M. Ruso st. 79, Nicosia, N. Cyprus).

\section{Please cite this article in English as:}

Eremichev A. Uniform Tension: the Problem and the Solution. Vestn. Mosk. Gos. Tekh. Univ. im. N.E. Baumana, Mashinostr. [Herald of the Bauman Moscow State Tech. Univ., Mech. Eng.], 2017, no. 5, pp. 22-27. DOI: 10.18698/0236-3941-2017-5-22-27

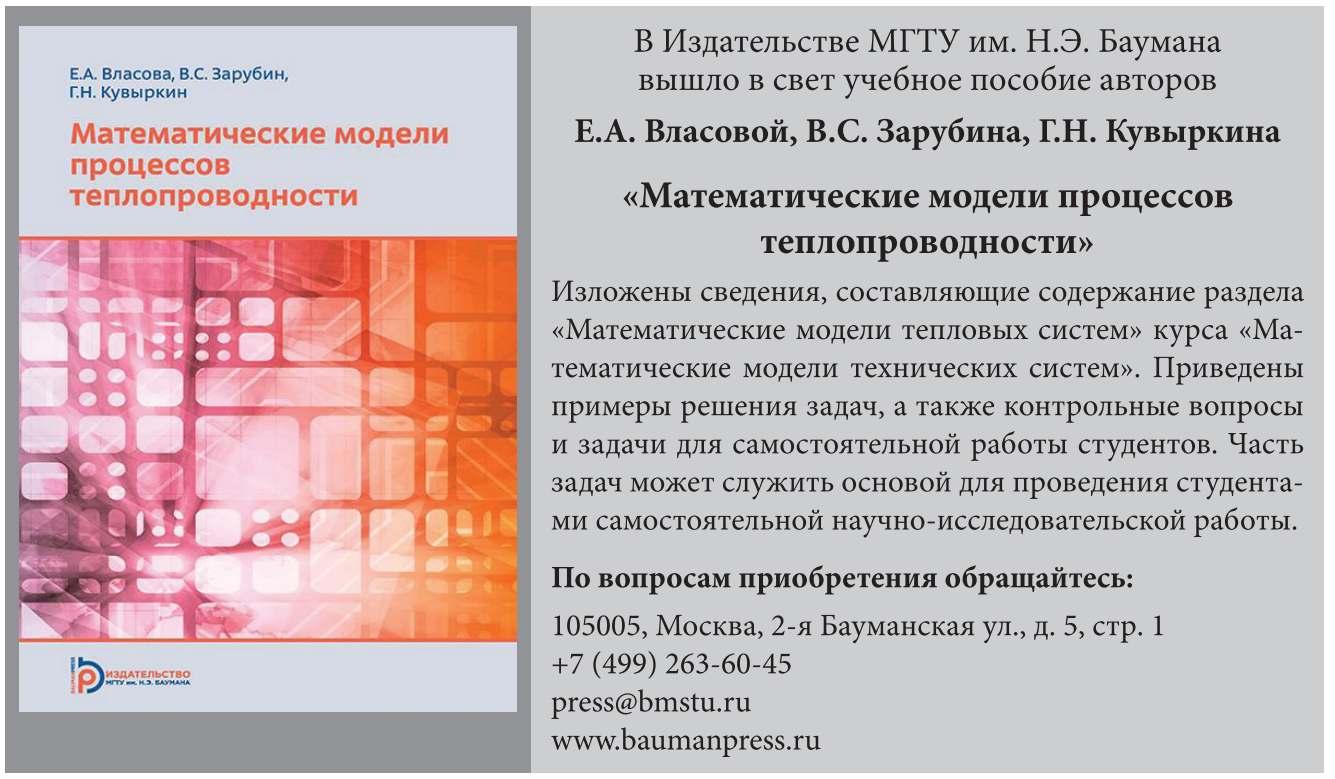

